\title{
Challenges in Prescribing Clozapine in the Era of COVID-19: A Review Focused on Immunological Implications
}

\author{
Seong Hoon Jeong', Yong Sik Kim ${ }^{2,3}$ \\ ${ }^{1}$ Department of Neuropsychiatry, Daejeon Eulji Medical Center, Eulji University School of Medicine, Daejeon, ${ }^{2}$ Department of Neuropsychiatry, \\ Nowon Eulji Medical Center, Eulji University School of Medicine, Seoul, ${ }^{3}$ Institute of Clinical Psychopharmacology, Dongguk University College \\ of Medicine, Goyang, Korea
}

\begin{abstract}
The global COVID-19 pandemic has disrupted every aspect of the healthcare system. Apart from the issues surrounding COVID-19 itself, care for existing patients has met many challenges. One such challenge is caring for patients who are on clozapine treatment and have been confirmed positive for COVID-19. Schizophrenia has been considered to have a deep connection with the immune system, and clozapine can induce further changes in this system. COVID-19 can ravage the compromised immune system and aggravate tissue damage. The intricate relations between schizophrenia, clozapine, and COVID-19 make it difficult to predict the clinical course of COVID-19 in clozapine-treated patients. However, the rigid prohibition on using clozapine if COVID-19 is confirmed may harm patients. Patients who have to use clozapine are often refractory cases with no alternatives. Therefore, the decision to maintain or stop clozapine must be made after a comprehensive review of the patient's unique situation. To do this, theoretical and practical issues surrounding the use of clozapine in COVID-19 should be reviewed and discussed. In this review, we gather useful information surrounding this issue and present an overview. Focusing on the immune system, various theoretical possibilities that could arise from schizophrenia, clozapine, and COVID-19 were carefully examined, and practical checklists for the care of these patients were explored. It is hoped that this review will convince many clinicians to pay attention to this momentous issue and facilitate more active sharing of clinical experiences.
\end{abstract}

KEY WORDS: Schizophrenia; Clozapine; COVID-19; Cytokines; Immunosenescence.

\section{INTRODUCTION}

For more than half a year, a highly contagious and potentially fatal pneumonia, officially called COVID-19, has swept the world, and caused havoc in peoples' daily lives. On March 11, 2020, WHO (World Health Organization) declared COVID-19 a pandemic and recognized it as a global health emergency. Since then, efforts to weaken the spread of COVID-19 have met with only a limited success. Developing an effective vaccine is likely to take several months, and we are now in a position to embrace the current situation and accept living with the virus for a

Received: September 17, 2020 / Revised: November 6, 2020 Accepted: November 9, 2020

Address for correspondence: Yonk Sik Kim

Department of Neuropsychiatry, Nowon Eulji Medical Center, Eulji University, 68 Hangeulbiseok-ro, Nowon-gu, Seoul 01830, Korea

E-mail: kys@snu.ac.kr

ORCID: https://orcid.org/0000-0002-8845-5186 while.

The concerns that COVID-19 introduced were not limited to the virus itself but covered a broader range of healthcare issues. For example, the number of visits to medical clinics has rapidly decreased due to fear of contracting COVID-19. Guidelines often recommend avoiding face-to-face contact with medical personnel [1]. It has been pointed out that patients requiring close medical care, such as cancer patients, already had difficulty receiving proper care [2]. Psychiatric patients, who have often been pushed to the margin in healthcare priorities, became even more alienated from adequate medical care.

Just as medical systems and clinical practice must be reorganized in light of COVID-19, the care of psychiatric patients also needs to be discussed in relation to COVID-19 [3]. One such example is the question of how to maintain clozapine treatment when COVID-19 is confirmed. This problem is especially urgent due to the unique

(ㄷ) This is an Open-Access article distributed under the terms of the Creative Commons Attribution Non-Commercial License (http://creativecommons.org/licenses/by-nc/4.0) which permits unrestricted non-commercial use, distribution, and reproduction in any medium, provided the original work is properly cited. 
status of clozapine due to its pharmacological properties and its role in refractory schizophrenia. Meanwhile, the cause of tissue damage and respiratory failure in COVID-19 is believed to be due to excessive host defenses rather than the action of the virus itself. Researchers have long suggested that the etiology of schizophrenia may be deeply rooted in immunological disturbance. A host of immune function abnormalities and elevated antibody titers to some viruses have been regularly found in patients with schizophrenia $[4,5]$. Furthermore, the actual prevalence of several viral infections tends to be higher in those with schizophrenia [6]. At the same time, clozapine has the potential to elicit pronounced changes in immune function [7]. Needless to say, there is no clear understanding as to how clozapine will affect the immune response to COVID-19. To use clozapine safely in this time of COVID-19, clinicians have to disentangle the complicated relationships between schizophrenia, clozapine, and COVID-19 by addressing the following questions:

1) Are patients on clozapine treatment at higher risk of contracting COVID-19?

2) When a patient on clozapine treatment is afflicted with COVID-19, does clozapine increase the likelihood of severe illness?

3) What issues should be considered when clozapine must be used in COVID-19 patients?

The following discussion will address these questions. The accumulated clinical data are limited, and no rigorous clinical studies have been conducted. Therefore, it may be difficult to draw any firm conclusions, but we hope that this study will draw the attention of clinicians to these issues and help them to engage in similar discussions in the future.

\section{BASIC INFORMATION}

Coronavirus disease (COVID-19) is caused by the SARS-CoV-2 virus, which encodes four proteins. One of them (the $S$ protein) binds to the host cell via the angiotensin-converting enzyme 2 (ACE2) cell surface receptor. ACE2 is mainly expressed on alveolar epithelial type II cells of the lung [8]. Infected individuals may only exhibit mild upper respiratory infection symptoms. However, severe cases show pneumonia, acute respiratory distress syndrome, renal failure, and death [9]. As of July, the global case fatality rate (CFR) was estimated to be around
$4 \%$, but this rate varies from $0.1 \%$ to $16.9 \%$ and is influenced by many variables. In Korea, the CFR was reported to be $2.1 \%[10]$.

\section{Immune Response in COVID-19}

Severe tissue damage in COVID-19 is caused not by viral toxicity but by the host immune response [11]. The immune response proceeds in two stages. During the incubation and early stages, cell-mediated defense by cytotoxic T-cells and/or natural killer (NK) cells predominates [11]. If this phagocytic defense is insufficient, the humoral response kicks in. The damaged cells induce inflammation, and the recruited macrophages and T lymphocytes release pro-inflammatory cytokines. These cytokines are strong inducers of hyaluronan-synthase-2 (HAS2), which produces hyaluronan (HA). HA has the ability to absorb water up to 1,000 times its molecular weight and clog the narrow airways in the lung. The intense inflammation and blocked airways are the main causes of respiratory failure [11,12].

One of the enigmas in COVID-19 has been the occurrence of lymphopenia without leukopenia [13]. A higher neutrophil-to-lymphocyte ratio (NLR) has been linked to more severe cases [14]. NK cells and cytotoxic T-cells are depleted at such a rapid pace that alternative measures must be taken [13]. The so-called "cytokine storm" is one such alternative measure [14]. It is an uncontrolled release of pro-inflammatory cytokines, such as interleukin (IL)-1, IL-6, IL-18, interferon (IFN)- $\gamma$, and tumor necrosis factor (TNF)- $\alpha$. Especially, IL- 6 is believed to be the key mediator [15]. Later release of anti-inflammatory cytokines including IL-10 follows, inducing immunoparalysis [16].

Initially, pro-inflammatory cytokines help to combat the virus by promoting the mobilization of cytotoxic T-cells. However, continuous stimulation of T-cells results in a phenomenon called "T-cell exhaustion" [17]. Although this is a common reaction to chronic viral infection, it occurs too early in COVID-19 [18]. Briefly, the cytokine storm can be described as a doomed effort to compensate for the failing cell-mediated immunity.

Immune responses orchestrated by T-cells are divided into Type 1 ( $\mathrm{TH} 1)$ and Type $2(\mathrm{TH} 2)$ responses. Naive helper T-cells (T0) develop into TH1 and TH2 helper cells according to the changing needs of the body [19]. $\mathrm{TH} 1 / \mathrm{TH} 2$ cells are responsible for cell-mediated and hu- 
moral responses, respectively. The delicate balance between the two systems is integral in the coordinated immune function. The early exhaustion of cytotoxic T-cells leads to $\mathrm{TH} 2$ dominance. However, the $\mathrm{TH} 2$ response is optimized for antibody production against extracellular pathogens such as parasites, and it is not very effective at controlling viral proliferation [20].

\section{Schizophrenia and Altered Immune Function}

The hypothesis that schizophrenia is deeply linked to immune dysfunction has been raised for decades [21]. Convincing evidence includes the genetic association of major histocompatibility complex alleles [22], increase in B-lymphocyte activity and antibody production [23], and imbalance in T-helper cell activity in favor of the $\mathrm{TH} 2$ system [24]. There is also growing evidence that low-grade neuroinflammation persists in a subset of psychotic patients for whom anti-inflammatory drugs can be beneficial [25]. Although schizophrenia is not a classic autoimmune disorder, the accompanying dysregulation of adaptive immunity and cellular immunity has been increasingly demonstrated. Given the inseparable connection between COVID-19 and the immune system, schizophrenia may have to be reinterpreted as an immunological disorder if we are to understand the unique COVID-19 risk imposed on patients with schizophrenia.

The so-called "TH2-shift theory of schizophrenia" was suggested based on the diminished release of IFN- $\gamma$ and the increased release of IL-4 and IL-10 in schizophrenia patients [24,26]. TH2-shift denotes diminished cellular immunity and overreliance on antibody-mediated defenses. An increase in immunoglobulins reacting to neuronal antigens or virus particles and an increased CD4+/CD8+ T-cell ratio in acute psychosis have been regarded as indirect evidence of a TH2-shift [27-29]. However, these pieces of evidence are weak and inconsistent, and the $\mathrm{TH} 1 / \mathrm{TH} 2$ directionality depends on the stage of illness, characteristics of the psychopathology, and the antipsychotic medication [30]. The higher NLR frequently observed in schizophrenic patients is also indicative of impaired cell-mediated immunity independent of overt infection $[31,32]$.

Evidence for cytokine alteration has been repeatedly found in schizophrenia patients [33,34]. IL-1 $\beta$, IL-6, IL-12, transforming growth factor (TGF)- $\beta$, and TNF- $\alpha$ are the cytokines most frequently reported to be elevated. These are mainly pro-inflammatory cytokines. IL-6 and IFN-I are especially important in maintaining and controlling microglial activity [35]. Increases in IL-6 and its soluble receptor sIL-6 have been reported in numerous studies [36,37]. While some studies found a state-dependent increase in cytokines during acute exacerbation of psychosis, more researchers have suggested a chronic, sensitized, pro-inflammatory state once called "smoldering inflammation" [21].

\section{Clozapine and Immunomodulation}

Shortly after clozapine was first introduced, the unexpected advent of potentially fatal agranulocytosis sparked active interest in its effects on the immune system. As early as 1993, papers reporting alteration of cytokine levels by clozapine began to appear [38,39]. It was believed to contribute to myocarditis, pericarditis, and serositis $[40,41]$. The frequent observation of hyperthermia in the early course of clozapine treatment is also related to cytokine disturbance [42].

Røge et al. [7] reviewed clozapine's immunomodulating effect and concluded that overall cytokine levels increase in the early phase of clozapine treatment and then normalize afterward. The increase in IL-6 levels was the most consistent finding [43]. Initially elevated IL-6 levels often returned to baseline after many months [44]. But in one study, IL-6 remained elevated in older, chronic patients on long-term clozapine treatment [45]. The time course is important, as clozapine's effect could be interpreted as pro-inflammatory in the early phase of treatment but anti-inflammatory in a later phase [46]. For example, clozapine inhibited the production of pro-inflammatory IL-6 and IL-8 in lipopolysaccharide stimulated macrophages, indicating that clozapine could inhibit TH1 differentiation by inhibiting $\mathrm{TH} 1$-inducing cytokines [47]. Similarly, in cell cultures under strong inflammatory activation by poly[l:C], clozapine reduced the levels of IL-1 $\alpha$, IL-1 $\beta$, IL-2, and IL-17. Clozapine exerts stronger anti-inflammatory effects than other antipsychotics [48]. The well-replicated result of a soluble IL-2 receptor (sIL-2R) increase with clozapine was also interpreted as immunosuppressive because clozapine binds to circulating IL-2 and decreases its bioavailability [49]. Thus, it could be hypothesized that the longer the treatment period, the more likely it becomes that clozapine will exhibit anti-inflammatory and immunosuppressive activity. 


\section{CLINICAL QUESTIONS}

\section{Are Patients on Clozapine Treatment at Higher Risk of Contracting COVID-19?}

The enclosed milieu of mental institutions, insufficient self-care, and the inability to follow social distance guidelines may expose patients to COVID-19. These concerns have led some clinicians to suspect increased risk of COVID-19 in patients with mental illness. But data are currently lacking to support this concern [50]. Nevertheless, it has been repeatedly noted that clozapine patients show a higher incidence of pneumonia. The odds ratio for contracting pneumonia among these patients compared with healthy controls was 4.07 [51]. This difference has often been attributed to sedation, sialorrhea, and difficulty swallowing, but many researchers have suggested that the immunosuppressive effects of clozapine are the culprit [52]. Govind et al. [53] compared the incidence of COVID-19 in clozapine patients with that in patients receiving other antipsychotics. The hazard ratio associated with clozapine was 2.62. However, the overall infection rate was only $1.66 \%$, and other confounding variables could not be adjusted.

These findings have led some researchers to argue that because clozapine patients are in a kind of immunocompromised state, they are at higher risk of contracting COVID-19 [54,55]. However, the suggestion that immunosuppression unconditionally makes the patient vulnerable to infection seems oversimplified. According to a survey, patients taking immunosuppressive or immunomodulatory medications were not distinguishable in terms of the incidence or severity of COVID-19 [56].

On the other hand, several psychoactive agents, including clozapine, have antiviral effects [57]. Clozapine inhibited the reactivation of the Epstein-Barr virus Iytic cycle in induced Burkitt lymphoma cells and some clozapine metabolites were found to suppress the replication of dengue virus, respiratory syncytial virus, rotavirus, and human immunodeficiency virus [58].

The effects of clozapine on the intracellular regulatory system involve endocytosis and autophagy. Viruses attached to extracellular receptors have to be engulfed to enter the cell. This process is called endocytosis. Pathogens often hijack the endocytosis machinery for penetration into the cytosol. Clathrin-dependent endocytosis and cathepsin-mediated S protein cleavage are two critical steps for coronavirus entry and infection [59].

In response to the infiltrating pathogen, host cells attempt to degrade it by autophagy [60]. Since this process may destroy the cell itself, it is delicately controlled by GSK-3 and its interaction with the PI3K/AKT/mTOR pathway [61]. Clozapine preferentially inhibits GSK-3 via modulating the PI3K/AKT pathway [62]. Because constitutive activation of GSK-3 suppresses autophagy by activating mTOR, GSK-3 inhibition has the net effect of increasing autophagic flux [63]. In this way, clozapine can activate autophagic defense mechanisms against the virus and help to dispose of virus-infected intracellular materials [60]. Inactivation of GSK-3 also facilitates the maintenance of lysosomal acidification, thus facilitating efficient virus clearing [64]. Recently, additional evidence has supported clozapine's effect in activating autophagy through the AMPK-ULK1-Beclin1 signaling pathway [65].

The role of autophagy in COVID-19 is hotly debated. Some viruses have evolved strategies to hijack autophagic machinery to infiltrate and replicate. Therefore, enhanced autophagy might facilitate viral entry. On the other hand, activated autophagy can help to target and destroy viruses [66]. Several endocytosis/autophagy inhibitors, including hydroxychloroquine, appear to have therapeutic potential in the treatment of COVID-19 [59]. Moreover, promoters including spermidine, MK-2206, and niclosamide have also been shown to inhibit coronavirus propagation [67].

Enhanced autophagy has been cited as a contributing factor in the superior effects of clozapine, but whether clozapine has a positive effect on COVID-19 remains to be seen $[65,68]$. This connection is being pursued by researchers who are trying to repurpose antipsychotic agents as anti-COVID-19 drugs [69,70].

\section{When a Patient on Clozapine Treatment is Afflicted with COVID-19, Does Clozapine Increase the Likelihood of Severe Illness?}

The major cause of severe pathology in COVID-19 has been assumed to be an uncheckable immune response. Thus, even if clozapine, an immunosuppressive agent, put patients at a greater risk of contracting COVID-19, symptom severity might also be attenuated because of the same immunosuppressive effect.

Superficially, stimulation of IL- 6 by clozapine resembles 
the cytokine storm. Pro-inflammatory states in the early phase of clozapine treatment may aggravate inflammation in COVID-19. However, favorable recovery from COVID-19 requires a delicate balance between microbial virulence and the host immune response. According to a theory called the disease response framework, the degree of host damage is a function of both forces [71]. Too little or too much immune response leads to the failure of successful defense, and this is especially true in COVID-19.

The close association between IL-6 and COVID-19 is worthy of concern. The most consistently elevated cytokine in schizophrenia and, coincidentally, specifically in clozapine patients, is IL-6 [44]. Clinical experience confirms that, especially in the early phase of treatment, clozapine provokes inflammatory states such as fever, elevation of C-reactive protein, serositis, myocarditis, pericarditis, eosinophilia [72,73]. Many clinicians believe that these inflammatory states will aggravate morbidity from this opportunistic infection [55], and others are concerned that the immunosuppressive effects of clozapine may undermine the defensive capacity of the host [74].

However, the actual connection is far more complicated than meets the eye. Inflammaging is a chronic lowgrade inflammation in aging individuals that is detected by prolonged elevation of pro-inflammatory cytokines [75]. NLR is also a marker associated with aging and is often found to be elevated in neuropsychiatric conditions such as schizophrenia, mood disorder, suicidal ideation, and cocaine use disorder $[76,77]$.

The two phenomena both reflect immunosenescence, which refers to a progressive reduction in the ability to defend associated with aging [78]. Based on this concept, some researchers have proposed the accelerated aging hypothesis of schizophrenia [79]. Most of the studies included in one review reported changes in the systemic markers of biological aging in schizophrenia patients [80]. Patients with greater disease severity and longer illness duration exhibited higher levels of inflammatory and oxidative stress [80].

In a neurodevelopmental model of schizophrenia, clozapine could reverse the increase in inducible nitric oxide synthase immunostaining, which reflects the degree of oxidative stress and microglial activation. Various epigenetic clocks have also verified the accelerated aging phenomenon in schizophrenia [81]. A recent study confirmed that several epigenetic clocks were advanced up to
5 years in schizophrenia patients [82]. Unexpectedly, they found that groups taking clozapine showed a significant decrease (about 3 to 7 years) in the chronological age indicated by these epigenetic clocks.

Whether this reversal by clozapine could prevent immunosenescence is as yet unclear. However, the anti-inflammatory and immunosuppressive effects of clozapine may delay the process of senescence. Clozapine could increase the production of IL-4 and IL-10, which are pleiotropic anti-inflammatory cytokines [30]. The serum concentrations of clozapine are inversely correlated with reactive oxygen species production by monocytes [83]. Clozapine could also protect dopaminergic neurons from inflammation-induced damage through inhibition of microglial NADPH oxidase [84].

In summary, it may be that schizophrenia patients have an immune system that is already senescent, exposing them to greater risk of severe COVID-19 pathology. However, clozapine may attenuate this risk by delaying accelerated aging and immunosenescence.

On the other hand, the anti-inflammatory properties of clozapine are likely to inhibit $\mathrm{TH} 1$ activation, thereby aggravating the $\mathrm{TH} 2$ shift [85]. Immunosenescence is generally coupled with an overall $\mathrm{TH} 2$ shift. Thus, clozapine's effects seem to be mutually incompatible [86]. One possible explanation is that if chronic low-grade activation of the $\mathrm{TH} 1$ system results in immunosenescence, clozapine may inhibit this unnecessary $\mathrm{TH} 1$ activation and save the reservoir capacity of the $\mathrm{TH} 1$ system to mount timely defenses against external pathogens. In our long evolutionary history, the body has developed several mechanisms to minimize host damage by reducing resistance to adverse stimuli that it cannot handle. In response to prolonged inflammatory conditions, CD4+/CD8+ T-cells gradually lose the ability to proliferate/differentiate, and they enter into a quiescent state, often called "T-cell exhaustion". Although this state is associated with inefficient control of infections and tumors, it serves as a mechanism to protect against extensive tissue damage [87]. It seems that maintaining a "stalemate" between the host and the pathogen by withholding active defense can save valuable immunological resources and help to prepare for an opportunity to counterattack. TH1 suppression by clozapine may also be understood as one of the evolutionary means to conserve resources and prevent total shutdown. 


\section{What Issues Should Be Considered When Clozapine Has to Be Used in COVID-19 Patients?}

\section{Initiation of clozapine in COVID-19 patients}

The worldwide spread of COVID-19 is a tremendous stressor for patients with schizophrenia. Social isolation and the fear provoked by media coverage can aggravate patients' paranoid tendencies. In patients who are already in a precarious balance, these stressors can promote relapse [50]. If these symptoms cannot be controlled, clozapine use may be urgently considered. However, initiating clozapine therapy in the time of COVID-19 presents several obstacles. Mandatory hematological monitoring increases the frequency of contact with medical personnel and heightens the risk of COVID-19 infection. The pro-inflammatory or occasional febrile state in the early phase of clozapine therapy may resemble the symptoms of COVID-19. The policies adopted by hospital administrations may require unnecessary isolation and repeated tests to rule out COVID-19 in this situation. If intensive care is required for sudden occurrence of agranulocytosis, it may be difficult to secure treatment facilities because those resources may already be occupied by COVID-19 patients.

\section{Alteration of clozapine concentration}

Infection can increase the clozapine concentration because released cytokines can inhibit CYP1A2, CYP2C19, and CYP3A4 $[88,89]$. Clozapine has a specific therapeutic range of approximately $350-600 \mathrm{ng} / \mathrm{mL}$. Common symptoms of toxicity are excessive sedation or change in consciousness level. Rarely, speech/gait impairment, hypersalivation, myoclonus, and even seizure could appear [90]. In certain cases, it may not be easy to differentiate toxicity symptoms from COVID-19 symptoms. Continuous monitoring of the concentration and adjustment of the dose would be ideal, but not every medical center is equipped with therapeutic drug monitoring (TDM) facilities.

If close monitoring of clozapine concentration is not available, de Leon et al. [54] recommended that the clozapine dose be cut in half. They also suggest that if signs of intoxication persist, clozapine should be immediately stopped. In the case of COVID, the same strategy would apply.

\section{Hematological alteration with clozapine}

The relative lymphopenia seen in COVID-19 raised concern that clozapine may further aggravate hematological abnormalities. Setting aside the risk of agranulocytosis, lurking hematological stress imposed by clozapine in genetically predisposed individuals should be addressed [91]. However, it should be noted that neutrophils are the cells most affected by clozapine, whereas it is lymphocytes that are quickly exhausted in COVID-19.

Clozapine is infrequently associated with coagulation abnormalities. Several case reports have documented both thrombocytosis and thrombopenia in clozapine patients $[92,93]$. Changes in the platelet count and overall thrombotic tendency are among the common findings in severe COVID-19 [94]. A predisposition to thrombosis increases the risk of blood clots, which may lead to ischemia or infarction [95]. Careful monitoring of platelet count and blood coagulation parameters is necessary.

Many guidelines recommend reducing the frequency of routine blood monitoring to every 3 months to prevent hospital-acquired infection. In this situation, it becomes more difficult to detect a sudden onset of agranulocytosis. Although direct contact with patients may decrease, other routes to check for signs and symptoms of infection should be arranged. Novel means of hematological monitoring with minimal interpersonal contact via point-ofcare devices should be considered [96].

\section{Field experience of clozapine maintenance in} COVID-19 patients

One case report described two successful cases: one for maintenance and another for initiation of clozapine therapy despite COVID-19 [97]. However, another report vividly demonstrated the difficulties involved. This patient experienced clozapine toxicity such that clozapine had to be abruptly stopped. Though he recovered from COVID-19, he suffered severe relapse of psychotic symptoms [98]. Similarly, another case series reported three patients who had developed serious clozapine toxicity in the process of maintaining clozapine during COVID-19 treatment [99].

Among 13 patients described by Gee et al. [100] three had died from complications. Clozapine had been maintained throughout the disease course, with dose adjustment. Although the fatality rate was higher $(23 \%)$ than usual, the sample size was too small to draw any conclusions. 
To assure safe maintenance of antipsychotics, including clozapine, in COVID-19 patients, many issues must be considered. Apart from immune abnormalities, multiple drug effects may confound the clinical picture. Typical concerns are sedation, swallowing difficulty, respiratory depression, QTC prolongation, coagulation risk and thromboembolism, delirium, or recurrence of psychotic symptoms. From this perspective, antipsychotic medi-

Table 1. General guideline for providing clozapine treatment in the time of COVID-19

\begin{tabular}{cc}
\hline \multicolumn{1}{c}{ Issue } & \multicolumn{1}{c}{ Recommendation } \\
\hline $\begin{array}{c}\text { Blood } \\
\text { monitoring }\end{array}$ & $\begin{array}{c}\text { Patients should continue with regular blood } \\
\text { monitoring whenever possible } \\
\text { The frequency of blood testing can be adjusted } \\
\text { balancing the risk of clozapine-induced blood } \\
\text { dyscrasia and unnecessary exposure to } \\
\text { coronavirus }^{\mathrm{a}}\end{array}$ \\
& \\
& $\begin{array}{c}\text { If a patient who is on weekly blood tests or } \\
\text { showed amber result cannot get blood test } \\
\text { on a scheduled date, rearrangement should } \\
\text { be made urgently }\end{array}$ \\
& $\begin{array}{c}\text { Decision to supply clozapine without a valid } \\
\text { blood test result may be taken to meet the } \\
\text { clozapine } \\
\text { needs of individual patient }\end{array}$
\end{tabular}

Medication delivery service

Prevention

$\begin{array}{ll}\text { If a patient is } & \text { Urgent and comprehensive physical } \\ \text { suspected of } & \text { examination } \\ \text { COVID-19 } & \text { Laboratory tests }\end{array}$

Adjust the dosage and watch out for clozapine toxicity even if COVID-19 is not confirmed ${ }^{d}$

\section{Specific details}

May be reduced to every 3 months if the following criteria met $(\text { Criteria } A)^{b}$ :

- Continuous clozapine treatment for $>1$ year

- Have never had an ANC $<2,000 / \mu \mathrm{L}$

- No safe or practical access to blood testing

For patients on clozapine for 6-12 months, decision should be made on individual bases ${ }^{b}$

For patients on clozapine for less than 6 months, the usual monitoring guideline should be followed ${ }^{b}$

- Attending the clinic on a different day

- Attending a different clinic/hospital elsewhere

- Nurse/doctor visit patient to take bloods

- A community team take bloods

The reasons for such decision should be fully explained to the patient and documented $^{\mathrm{a}}$

For patients fulfilling criteria A, 30-day supply of clozapine is possible without valid test result. However, a 60- or 90-day supply may be prudent if patients remain at high risk contacting COVID-19 ${ }^{\mathrm{d}}$

For patients on clozapine for less than 6 months, only 1- or 2-weeks supply is recommended ${ }^{d}$

Legal liability of physicians and drug suppliers would have to be temporarily relieved or loosened to comply with the above guideline until the pandemic crisis is over ${ }^{\mathrm{e}}$

Home delivery of medication is recommended for patients isolated or confined due to COVID-19 risk $^{f}$

- Address hypersalivationprevent aspiration pneumonia ${ }^{f}$

- Vaccinate for influenza and pneumococcal disease ${ }^{f}$

- Help and persuade patients to stop or reduce smoking ${ }^{\mathrm{f}}$

Be aware that similar symptoms can arise from incidental infections associated with neutropenia ${ }^{a}$

- CBC: differentiate between COVID-19 and blood dyscrasia

- Troponins: myocarditis

- CRP, D-dimer: measure of pro-inflammatory status

- LFT: increased rate of hepatic dysfunction

- ECG: QTC prolongation

- Oxygen saturation: respiratory distress

Consider reducing the dose of clozapine by as much as a half

Continue the lower dose until 3 days after the fever has subsided, then increase clozapine in a stepwise manner to the pre-fever dose Use therapeutic drug monitoring if possible

The content of this guideline has been compiled and summarized from various sources.

ANC, absolute neutrophil count; FDA, U.S. Food and Drug Administration.

${ }^{a}$ Royal College of Psychiatrists Guideline (https://www.rcpsych.ac.uk/about-us/responding-to-covid-19/responding-to-covid-19-guidance-for-clinicians/ community-and-inpatient-services/providing-medication). ${ }^{b}$ Siskind et al. [1]. ' College of Mental Health Pharmacy Guideline (https://www.rpharms.com/ Portals/0/RPS\%20document\%20library/Open\%20access/Coronavirus/CMHP\%20Monitoring\%20and\%20Supply\%20of\%20Clozapine\%20durin g\%20Covid-19\%20Pandemic-RPSendorsed.pdf?ver=2020-03-31-103408-973). ${ }^{\mathrm{d} U p t o D a t e ~ G u i d e l i n e ~(h t t p s: / / m w w . u p t o d a t e . c o m / c o n t e n t s / g u i d e l i n e s-f o r-~}$ prescribing-clozapine-in-schizophrenia\#H1404562173). ${ }^{e}$ FDA: Policy for Certain REMS Requirements During the COVID-19 Public Health Emergency (https://www.fda.gov/media/136317/download). 'New South Wales Ministry of Health of Australia (https://www.health.nsw.gov.au/Infectious/ covid-19/communities-of-practice/Pages/guide-clozapine-management.aspx). 
cations may have to be reduced or stopped to safeguard patients' physical health. However, for some patients, psychotropic treatments are essential and should be maintained even at some risk. There is no absolute guideline for these difficult decisions, and we have no choice but to do our best to achieve a delicate balance, guided by the individual's unique situation [100].

\section{Recommended guidelines}

As yet, no official guideline has been established for clozapine patients with suspected COVID-19. However, various health-related institutions have prepared and implemented their own guidelines, and the contents are generally consistent [1]. Essential contents of these guidelines were assembled and are summarized in Table 1.

\section{CONCLUSION}

As we have seen so far, many clinicians have expressed concern regarding the use of clozapine in COVID-19 patients. Even before the advent of COVID-19, patients on clozapine were observed to have a higher incidence of pneumonia. Some considered that this was due to the pro-inflammatory state triggered by clozapine, and others pointed to its immunosuppressive effect. Because of this, clinicians worried that the patients using clozapine would be at a higher risk of COVID-19 and would suffer from severe symptoms if they contracted COVID-19.

However, clozapine may have been the last drug of choice for refractory patients. Moreover, because relapse after withdrawal is quite abrupt and severe, switching to other drugs may be difficult. The clinician has to decide between the patient's physical health and the severity of the psychotic symptoms.

Consensus guidelines recommend that the decision to use clozapine be made after a comprehensive review of the patient's unique situation. Once a decision has been made, the clozapine dose should be adjusted and TDM or toxicity monitoring implemented. Unfortunately, these guidelines only apply to mild to moderate cases. There is no standard operating procedure for severe cases placed in intensive care units.

Superficially, by disrupting the cytokine network and suppressing immune function, clozapine would appear to have only negative effects on COVID-19. However, the interrelationships between schizophrenia, clozapine, and
COVID-19 are trickier to entangle, as schizophrenia itself is accompanied by immunological disturbances. Solving this unyielding puzzle will be an extremely difficult process and, at the same time, an urgent task to undertake. Above all, severe host damage in COVID-19 occurs not because of the virus itself but because of the host's uncoordinated immune response. After an initial defense, the host's immune system spirals into T-cell exhaustion much sooner than expected. Then, too much cytokine is secreted to compensate, leading to a cytokine storm. Clozapine's effect on the immune system may help to dampen this intense reaction.

Convincing evidence exists concerning the $\mathrm{TH} 2$ shift and immunosenescence in patients with schizophrenia. Thus, even before they contract COVID-19, cell-mediated immunity is already handicapped in these patients. If coronavirus invades in this state, T-cell exhaustion may begin earlier than in the healthy individual. If immunosenescence could be reversed or delayed by clozapine, it may help to replenish immunological resources against COVID-19. Likewise, immunosuppressive effects may delay T-cell exhaustion and prevent a fatal cytokine storm.

The wide-ranging effect of clozapine beyond its effect on neurotransmitter receptors might influence COVID-19 in unexpected ways. Clozapine can interrupt various intracellular signaling pathways, one of which is responsible for endocytosis/autophagy. This pathway is deeply involved with viral entry and replication, so clozapine may block or facilitate viral entry.

At the moment, there are only a couple of case reports of COVID-19 in schizophrenia patients taking clozapine. Guidelines are scant and inconsistent in their recommendations, but they all emphasize rapid implementation of measures to both decrease the risk of COVID-19 transmission and maintain continuity of clinical care $[1,101]$. As clinicians encounter more cases and actively share them with other clinicians, it is expected that more authorized guidelines will be established. It is hoped that this review will convince many clinicians to pay attention to this momentous issue and facilitate more active sharing of clinical experiences.

\section{- Conflicts of Interest}

No potential conflict of interest relevant to this article was reported. 


\section{Author Contributions}

Conceptualization: Yong Sik Kim. Data acquisition \& Formal analysis: Seong Hoon Jeong. Supervision: Yong Sik Kim. Writing-original draft: Seong Hoon Jeong. Writing - review \& editing: Yong Sik Kim.

\section{ORCID}

Seong Hoon Jeong https://orcid.org/0000-0002-7404-9056 Yong Sik Kim https://orcid.org/0000-0002-8845-5186

\section{REFERENCES}

1. Siskind D, Honer WG, Clark S, Correll CU, Hasan A, Howes $\mathrm{O}$, et al. Consensus statement on the use of clozapine during the COVID-19 pandemic. I Psychiatry Neurosci 2020;45: 222-223.

2. Tsamakis K, Gavriatopoulou M, Schizas D, Stravodimou A, Mougkou A, Tsiptsios D, et al. Oncology during the COVID-19 pandemic: challenges, dilemmas and the psychosocial impact on cancer patients. Oncol Lett 2020;20: 441-447.

3. Kreuzer PM, Baghai TC, Rupprecht R, Wittmann M, Steffling $\mathrm{D}$, Ziereis $\mathrm{M}$, et al. SARS-CoV-2 risk management in clinical psychiatry: a few considerations on how to deal with an unrivaled threat. Front Psychiatry 2020;11:550.

4. Dickerson F, Jones-Brando L, Ford G, Genovese G, Stallings C, Origoni A, et al. Schizophrenia is associated with an aberrant immune response to Epstein-Barr virus. Schizophr Bull 2019;45:1112-1119.

5. Burgdorf KS, Trabjerg BB, Pedersen MG, Nissen J, Banasik K, Pedersen OB, et al. Large-scale study of Toxoplasma and cytomegalovirus shows an association between infection and serious psychiatric disorders. Brain Behav Immun 2019;79: 152-158.

6. Nudel R, Benros ME, Krebs MD, Allesøe RL, Lemvigh CK, Bybjerg-Grauholm J, et al. Immunity and mental illness: findings from a Danish population-based immunogenetic study of seven psychiatric and neurodevelopmental disorders. Eur J Hum Genet 2019;27:1445-1455.

7. Røge R, Møller BK, Andersen CR, Correll CU, Nielsen J. Immunomodulatory effects of clozapine and their clinical implications: what have we learned so far? Schizophr Res 2012;140:204-213.

8. Walls AC, Park YJ, Tortorici MA, Wall A, McGuire AT, Veesler D. Structure, function, and antigenicity of the SARSCoV-2 spike glycoprotein. Cell 2020;181:281-292.e6.

9. Zhang JJ, Dong X, Cao YY, Yuan YD, Yang YB, Yan YQ, et al. Clinical characteristics of 140 patients infected with SARSCoV-2 in Wuhan, China. Allergy 2020;75:1730-1741.

10. Kim DH, Choe YJ, Jeong JY. Understanding and interpretation of case fatality rate of coronavirus disease 2019. I
Korean Med Sci 2020;35:e137.

11. Shi $Y$, Wang $Y$, Shao $C$, Huang J, Gan J, Huang $X$, et al. COVID-19 infection: the perspectives on immune responses. Cell Death Differ 2020;27:1451-1454.

12. Prieto-Pérez L, Fortes J, Soto C, Vidal-González Á, AlonsoRiaño M, Lafarga M, et al. Histiocytic hyperplasia with hemophagocytosis and acute alveolar damage in COVID-19 infection. Mod Pathol 2020;33:2139-2146.

13. Fathi N, Rezaei N. Lymphopenia in COVID-19: therapeutic opportunities. Cell Biol Int 2020;44:1792-1797.

14. Ragab D, Salah Eldin H, Taeimah M, Khattab R, Salem R. The COVID-19 cytokine storm; what we know so far. Front Immunol 2020;11:1446.

15. Ruan Q, Yang K, Wang W, Jiang L, Song J. Clinical predictors of mortality due to COVID-19 based on an analysis of data of 150 patients from Wuhan, China. Intensive Care Med 2020;46:846-848.

16. Picchianti Diamanti A, Rosado MM, Pioli $C$, Sesti G, Laganà B. Cytokine release syndrome in COVID-19 patients, a new scenario for an old concern: the fragile balance between infections and autoimmunity. Int J Mol Sci 2020;21:3330.

17. Kahan SM, Wherry EJ, Zajac AJ. T cell exhaustion during persistent viral infections. Virology 2015;479-480:180-193.

18. Diao B, Wang C, Tan Y, Chen X, Liu Y, Ning L, et al. Reduction and functional exhaustion of t cells in patients with coronavirus disease 2019 (COVID-19). Front Immunol 2020; 11:827.

19. Berger A. Th1 and Th2 responses: what are they? BMJ 2000; 321:424.

20. Kidd P. Th1/Th2 balance: the hypothesis, its limitations, and implications for health and disease. Altern Med Rev 2003;8: 223-246.

21. Müller N. Inflammation in schizophrenia: pathogenetic aspects and therapeutic considerations. Schizophr Bull 2018; 44:973-982.

22. Mokhtari R, Lachman HM. The major histocompatibility complex (MHC) in schizophrenia: a review. J Clin Cell Immunol 2016;7:479.

23. Steiner J, Jacobs R, Panteli B, Brauner M, Schiltz K, Bahn S, et al. Acute schizophrenia is accompanied by reduced $T$ cell and increased B cell immunity. Eur Arch Psychiatry Clin Neurosci 2010;260:509-518.

24. Schwarz MJ, Müller N, Riedel M, Ackenheil M. The Th2-hypothesis of schizophrenia: a strategy to identify a subgroup of schizophrenia caused by immune mechanisms. Med Hypotheses 2001;56:483-486.

25. Pollak TA, Lennox BR, Müller S, Benros ME, Prüss H, Tebartz van Elst L, et al. Autoimmune psychosis: an international consensus on an approach to the diagnosis and management of psychosis of suspected autoimmune origin. Lancet Psychiatry 2020;7:93-108.

26. Chiang SS, Riedel M, Schwarz M, Mueller N. Is T-helper type 2 shift schizophrenia-specific? Primary results from a com- 
parison of related psychiatric disorders and healthy controls. Psychiatry Clin Neurosci 2013;67:228-236.

27. Miller BJ, Gassama B, Sebastian D, Buckley P, Mellor A. Meta-analysis of lymphocytes in schizophrenia: clinical status and antipsychotic effects. Biol Psychiatry 2013;73:993-999.

28. Ezeoke A, Mellor A, Buckley P, Miller B. A systematic, quantitative review of blood autoantibodies in schizophrenia. Schizophr Res 2013;150:245-251.

29. Mohagheghi M, Eftekharian MM, Taheri M, Alikhani MY. Determining the IgM and IgG antibodies titer against HSV1, HSV2 and CMV in the serum of schizophrenia patients. Hum Antibodies 2018;26:87-93.

30. Al-Amin MM, Nasir Uddin MM, Mahmud Reza H. Effects of antipsychotics on the inflammatory response system of patients with schizophrenia in peripheral blood mononuclear cell cultures. Clin Psychopharmacol Neurosci 2013;11: 144-151.

31. Karageorgiou V, Milas GP, Michopoulos I. Neutrophil-tolymphocyte ratio in schizophrenia: a systematic review and meta-analysis. Schizophr Res 2019;206:4-12.

32. Kulaksizoglu B, Kulaksizoglu S. Relationship between neutrophil/lymphocyte ratio with oxidative stress and psychopathology in patients with schizophrenia. Neuropsychiatr Dis Treat 2016;12:1999-2005.

33. Müller N, Weidinger E, Leitner B, Schwarz MJ. The role of inflammation in schizophrenia. Front Neurosci 2015;9:372.

34. Momtazmanesh S, Zare-Shahabadi A, Rezaei N. Cytokine alterations in schizophrenia: an updated review. Front Psychiatry 2019;10:892.

35. West PK, Viengkhou B, Campbell IL, Hofer MJ. Microglia responses to interleukin-6 and type I interferons in neuroinflammatory disease. Glia 2019;67:1821-1841.

36. Al-Hakeim HK, Al-Rammahi DA, Al-Dujaili AH. IL-6, IL-18, $s / L-2 R$, and $T N F \alpha$ proinflammatory markers in depression and schizophrenia patients who are free of overt inflammation. J Affect Disord 2015;182:106-114.

37. Goldsmith DR, Rapaport MH, Miller BJ. A meta-analysis of blood cytokine network alterations in psychiatric patients: comparisons between schizophrenia, bipolar disorder and depression. Mol Psychiatry 2016;21:1696-1709.

38. Sperner-Unterweger B, Gaggl S, Fleischhacker WW, Barnas C, Herold M, Geissler D. Effects of clozapine on hematopoiesis and the cytokine system. Biol Psychiatry 1993;34:536-543.

39. Maes M, Meltzer HY, Bosmans E. Immune-inflammatory markers in schizophrenia: comparison to normal controls and effects of clozapine. Acta Psychiatr Scand 1994;89: 346-351.

40. Merrill DB, Dec GW, Goff DC. Adverse cardiac effects associated with clozapine. J Clin Psychopharmacol 2005;25: $32-41$.

41. Mouaffak F, Gaillard R, Burgess E, Zaki H, Olié JP, Krebs MO. Clozapine-induced serositis: review of its clinical features, pathophysiology and management strategies. Clin
Neuropharmacol 2009;32:219-223.

42. Lowe CM, Grube RR, Scates AC. Characterization and clinical management of clozapine-induced fever. Ann Pharmacother 2007:41:1700-1704.

43. Löffler S, Klimke A, Kronenwett R, Kobbe G, Haas R, Fehsel K. Clozapine mobilizes CD34+ hematopoietic stem and progenitor cells and increases plasma concentration of interleukin 6 in patients with schizophrenia. J Clin Psychopharmacol 2010;30:591-595.

44. Maes M, Bosmans E, Kenis G, De Jong R, Smith RS, Meltzer $\mathrm{HY}$. In vivo immunomodulatory effects of clozapine in schizophrenia. Schizophr Res 1997;26:221-225.

45. Schmitt A, Bertsch T, Tost H, Bergmann A, Henning U, Klimke A, et al. Increased serum interleukin-1beta and interleukin-6 in elderly, chronic schizophrenic patients on stable antipsychotic medication. Neuropsychiatr Dis Treat 2005; 1:171-177.

46. Song C, Lin Ah, Kenis G, Bosmans E, Maes M. Immunosuppressive effects of clozapine and haloperidol: enhanced production of the interleukin-1 receptor antagonist. Schizophr Res 2000;42:157-164.

47. Chen ML, Tsai TC, Wang LK, Lin YY, Tsai YM, Lee MC, et al. Clozapine inhibits Th1 cell differentiation and causes the suppression of IFN- $\gamma$ production in peripheral blood mononuclear cells. Immunopharmacol Immunotoxicol 2012;34: 686-694.

48. Giridharan VV, Scaini G, Colpo GD, Doifode T, Pinjari OF, Teixeira AL, et al. Clozapine prevents poly $(1: C)$ induced inflammation by modulating NLRP3 pathway in microglial cells. Cells 2020;9:577.

49. Gooding R, Riches P, Dadian G, Moore J, Gore M. Increased soluble interleukin-2 receptor concentration in plasma predicts a decreased cellular response to IL-2. BrJ Cancer 1995; 72:452-455.

50. Barber S, Reed L, Syam N, Jones N. Severe Mental IIIness and Risks from COVID-19 [Internet]. Oxford: Centre for EvidenceBased Medicine; 2020 [cited at 2020 Oct 6]. Available from: https://www.cebm.net/covid-19/severe-mental-il/nessand-risks-from-covid-19/.

51. Stoecker ZR, George WT, O’Brien JB, Jancik J, Colon E, Rasimas JJ. Clozapine usage increases the incidence of pneumonia compared with risperidone and the general population: a retrospective comparison of clozapine, risperidone, and the general population in a single hospital over 25 months. Int Clin Psychopharmacol 2017;32:155-160.

52. Abdelmawla N, Ahmed Ml. Clozapine and risk of pneumonia. BrJ Psychiatry 2009;194:468-469.

53. Govind R, Fonseca de Freitas D, Pritchard M, Hayes RD, MacCabe JH. Clozapine treatment and risk of COVID-19 infection: retrospective cohort study. BrJ Psychiatry 2020. doi: 10.1192/bjp.2020.151. [Epub ahead of print]

54. de Leon J, Ruan CJ, Schoretsanitis G, De Las Cuevas C. A rational use of clozapine based on adverse drug reactions, 
pharmacokinetics, and clinical pharmacopsychology. Psychother Psychosom 2020;89:200-214.

55. de Leon J, Ruan CJ, Verdoux H, Wang C. Clozapine is strongIy associated with the risk of pneumonia and inflammation. Gen Psychiatr 2020;33:e100183.

56. Fung $\mathrm{M}$, Babik JM. COVID-19 in immunocompromised hosts: what we know so far. Clin Infect Dis 2020. doi: 10.1093/cid/ciaa863. [Epub ahead of print]

57. Amaral L, Viveiros M, Molnar J. Antimicrobial activity of phenothiazines. In Vivo 2004;18:725-731.

58. Anderson AG, Gaffy CB, Weseli JR, Gorres KL. Inhibition of Epstein-Barr virus lytic reactivation by the atypical antipsychotic drug clozapine. Viruses 2019;11:450.

59. Yang N, Shen HM. Targeting the endocytic pathway and autophagy process as a novel therapeutic strategy in COVID-19. Int J Biol Sci 2020;16:1724-1731.

60. Cavignac Y, Esclatine A. Herpesviruses and autophagy: catch me if you can! Viruses 2010;2:314-333.

61. Mancinelli R, Carpino G, Petrungaro S, Mammola CL, Tomaipitinca L, Filippini A, et al. Multifaceted roles of GSK-3 in cancer and autophagy-related diseases. OxidMed Cell Longev 2017;2017:4629495.

62. Kang UG, Seo MS, Roh MS, Kim Y, Yoon SC, Kim YS. The effects of clozapine on the GSK-3-mediated signaling pathway. FEBS Lett 2004;560:115-119.

63. Azoulay-Alfaguter I, Elya R, Avrahami L, Katz A, EldarFinkelman H. Combined regulation of mTORC1 and lysosomal acidification by GSK-3 suppresses autophagy and contributes to cancer cell growth. Oncogene 2015;34:46134623.

64. Avrahami L, Paz R, Dominko K, Hecimovic S, Bucci C, Eldar-Finkelman H. GSK-3-TSC axis governs lysosomal acidification through autophagy and endocytic pathways. Cell Signal 2020;71:109597.

65. Kim SH, Park S, Yu HS, Ko KH, Park HG, Kim YS. The antipsychotic agent clozapine induces autophagy via the AMPK-ULK1-Beclin1 signaling pathway in the rat frontal cortex. Prog Neuropsychopharmacol Biol Psychiatry 2018; 81:96-104.

66. Mijaljica D, Klionsky DJ. Autophagy/virophagy: a "disposal strategy" to combat COVID-19. Autophagy 2020;16:22712272.

67. Gassen NC, Papies J, Bajaj T, Dethloff F, Emanuel J, Weckmann K, et al. Analysis of SARS-CoV-2-controlled autophagy reveals spermidine, MK-2206, and niclosamide as putative antiviral therapeutics. BioRxiv 997254 [Preprint]. 2020 [cited 2020 Oct 6]. Available from: https://doi.org/10.1101/2020.04.15.997254.

68. Kim SH, Yu HS, Park S, Park HG, Ahn YM, Kang UG, et al. Electroconvulsive seizures induce autophagy by activating the AMPK signaling pathway in the rat frontal cortex. Int I Neuropsychopharmacol 2020;23:42-52.

69. Villoutreix BO, Beaune PH, Tamouza R, Krishnamoorthy R,
Leboyer M. Prevention of COVID-19 by drug repurposing: rationale from drugs prescribed for mental disorders. Drug Discov Today 2020;25:1287-1290.

70. Plaze M, Attali D, Petit AC, Blatzer M, Simon-Loriere E, Vinckier $\mathrm{F}$, et al. [Repurposing of chlorpromazine in COVID-19 treatment: the reCoVery study]. Encephale 2020;46(3S):S35-S39. French.

71. Pirofski LA, Casadevall A. Pathogenesis of COVID-19 from the perspective of the damage-response framework. $\mathrm{mBio}$ 2020;11:e01175-20.

72. Stuhec M. Clozapine-induced elevated C-reactive protein and fever mimic infection. Gen Hosp Psychiatry 2013;35: 680.e5-6.

73. Kadiyala PK, Ahmed MA, Pinto DA, Mathai JP. Clozapine induced eosinophilia: an often neglected important adverse effect. Indian J Psychiatry 2015;57:429-430.

74. Ponsford M, Castle D, Tahir T, Robinson R, Wade W, Steven $\mathrm{R}$, et al. Clozapine is associated with secondary antibody deficiency. Br J Psychiatry 2018;214:1-7.

75. Fülöp T, Larbi A, Witkowski JM. Human inflammaging. Gerontology 2019;65:495-504.

76. Valiathan R, Ashman M, Asthana D. Effects of ageing on the immune system: infants to elderly. Scand I Immunol 2016; 83:255-266.

77. Soder HE, Berumen AM, Gomez KE, Green CE, Suchting R, Wardle MC, et al. Elevated neutrophil to lymphocyte ratio in older adults with cocaine use disorder as a marker of chronic inflammation. Clin Psychopharmacol Neurosci 2020;18: $32-40$.

78. Franceschi $C$, Bonafè $M$, Valensin S, Olivieri F, De Luca $M$, Ottaviani $\mathrm{E}$, et al. Inflamm-aging. An evolutionary perspective on immunosenescence. Ann N Y Acad Sci 2000; 908:244-254.

79. Shivakumar V, Kalmady SV, Venkatasubramanian G, Ravi V, Gangadhar BN. Do schizophrenia patients age early? Asian J Psychiatr 2014;10:3-9.

80. Nguyen TT, Eyler LT, Jeste DV. Systemic biomarkers of accelerated aging in schizophrenia: a critical review and future directions. Schizophr Bull 2018;44:398-408.

81. Okazaki S, Otsuka I, Numata S, Horai T, Mouri K, Boku S, et al. Epigenetic clock analysis of blood samples from Japanese schizophrenia patients. NPJ Schizophr 2019;5:4.

82. Higgins-Chen AT, Boks MP, Vinkers $\mathrm{CH}$, Kahn RS, Levine ME. Schizophrenia and epigenetic aging biomarkers: increased mortality, reduced cancer risk, and unique clozapine effects. Biol Psychiatry 2020;88:224-235.

83. Gross A, Joffe G, Joutsiniemi SL, Nyberg P, Rimón R, Appelberg B. Decreased production of reactive oxygen species by blood monocytes caused by clozapine correlates with EEG slowing in schizophrenic patients. Neuropsychobiology 2003:47:73-77.

84. Jiang L, Wu X, Wang S, Chen SH, Zhou H, Wilson B, et al. Clozapine metabolites protect dopaminergic neurons through 
inhibition of microglial NADPH oxidase. J Neuroinflammation 2016; 13:110.

85. Couper KN, Blount DG, Riley EM. IL-10: the master regulator of immunity to infection. J Immunol 2008;180:5771-5777.

86. Sandmand M, Bruunsgaard H, Kemp K, Andersen-Ranberg $\mathrm{K}$, Pedersen AN, Skinhøj $\mathrm{P}$, et al. Is ageing associated with a shift in the balance between Type 1 and Type 2 cytokines in humans? Clin Exp Immunol 2002;127:107-114.

87. Wherry EJ, Kurachi M. Molecular and cellular insights into $T$ cell exhaustion. Nat Rev Immunol 2015;15:486-499.

88. de Leon J, Diaz FJ. Serious respiratory infections can increase clozapine levels and contribute to side effects: a case report. Prog Neuropsychopharmacol Biol Psychiatry 2003; 27:1059-1063.

89. Shah RR, Smith RL. Inflammation-induced phenoconversion of polymorphic drug metabolizing enzymes: hypothesis with implications for personalized medicine. Drug Metab Dispos 2015:43:400-410.

90. Clark SR, Warren NS, Kim G, Jankowiak D, Schubert KO, Kisely $\mathrm{S}$, et al. Elevated clozapine levels associated with infection: a systematic review. Schizophr Res 2018;192:50-56.

91. Wiciński M, Węclewicz MM. Clozapine-induced agranulocytosis/granulocytopenia: mechanisms and monitoring. Curr Opin Hematol 2018;25:22-28.

92. Hampson ME. Clozapine-induced thrombocytosis. Br J Psychiatry 2000;176:400.

93. Kate N, Grover S, Aggarwal M, Malhotra P, Sachdeva MS.
Clozapine associated thrombocytopenia. I Pharmacol Pharmacother 2013;4:149-151.

94. Wise J. Covid-19 and thrombosis: what do we know about the risks and treatment? BMJ 2020;369:m2058.

95. Levi M, Thachil J, Iba T, Levy JH. Coagulation abnormalities and thrombosis in patients with COVID-19. Lancet Haematol 2020;7:e438-e440.

96. Leung JG, Wittenberger TS, Schak KM. Clozapine treated patients and COVID-19: ensuring continued care through collaboration. Schizophr Res 2020;222:507-508.

97. Boland X, Dratcu L. Clozapine in the time of COVID-19. Clin Psychopharmacol Neurosci 2020;18:450-453.

98. Cranshaw T, Harikumar T. COVID-19 infection may cause clozapine intoxication: case report and discussion. Schizophr Bull 2020;46:751.

99. Dotson S, Hartvigsen N, Wesner T, Carbary TJ, Fricchione G, Freudenreich O. Clozapine toxicity in the setting of COVID-19. Psychosomatics 2020;61:577-578.

100. Gee S, Gaughran F, MacCabe J, Shergill S, Whiskey E, Taylor D. Management of clozapine treatment during the COVID-19 pandemic. Ther Adv Psychopharmacol 2020. doi: $10.1177 / 2045125320928167$.

101. Kozloff N, Mulsant BH, Stergiopoulos V, Voineskos AN. The COVID-19 global pandemic: implications for people with schizophrenia and related disorders. Schizophr Bull 2020; 46:752-757. 